\title{
UMA ANÁLISE DO ENSINO JURÍDICO NO BRASIL
}

\section{Nathalie de Paula Carvalho}

Mestra em Direito Constitucional (Unifor). Especialista em Direito e Processo Constitucional (Unifor). Especialista em Direito e Processo do Trabalho (UVA). Professora do curso de Direito da Unifor. Advogada. Trabalho orientado pelo prof. dr. Rosendo Amorim (Unifor). nathaliedireito@hotmail.com

Sumário: Introdução. 1. A realidade do ensino jurídico no Brasil. 2. O procedimento adotado no ensino jurídico. 3. Como melhorar o ensino jurídico no Brasil? Conclusão. Referências.

É preciso, porém, que tenhamos na resistência que nos preserva vivos, na compreensão do futuro como problema e na vocação para o ser mais como expressão da natureza humana em processo de estar sendo, fundamentos para a nossa rebeldia e não para a nossa resignação em face das ofensas que nos destroem o ser. Não é na resignação, mas na rebeldia em face das injustiças que nos afirmamos ${ }^{1}$.

Resumo: Este artigo tem por escopo analisar a questão do ensino jurídico no Brasil, investigar os principais motivos da sua má qualidade e, ao final, apresentar algumas sugestões que visem aprimorá-lo e sanar os principais problemas. Parte-se de uma breve contextualização da situação dos docentes e discentes nos cursos de Direito, dando-se um maior enfoque à democratização do ensino, principalmente o jurídico, de modo a investigar as vantagens e desvantagens desse fenômeno. Conclui-se pela necessidade de um maior controle por parte dos órgãos e entidades responsáveis, de modo a orientar a classe de estudantes e professores a buscar um aprendizado cada vez mais contributivo para a sociedade, bem como a exigência de uma postura ética por parte dos envolvidos no processo ensino-aprendizagem.

Palavras-chave: Ensino jurídico. Democratização. Fiscalização. Ética.

\section{INTRODUÇÃO}

A situação atual do ensino jurídico, marcada pela má qualidade, é provocada, principalmente, pela massificação do ingresso nas universidades; pelo

FREIRE, Paulo. Pedagogia como autonomia: saberes necessários à prática educativa. 30. ed. São Paulo: Paz e terra, 1996, p. 78. 
despreparo dos alunos provenientes de um ensino médio deficitário; pela desvalorização das respectivas profissões, o que enseja o direcionamento para o sistema universitário não por vocação, mas como caminho para uma participação qualificada no mercado de trabalho, dentre outros fatores que serão abordados adiante.

A maior preocupação do meio acadêmico contemporâneo é com a instituição de técnicas e perspectivas voltadas para a eficiência, o que vem imprimindo ao Direito uma visão técnico-legal, de modo a afastá-lo cada vez mais da realidade social, cultural e política que o cerca.

Constata-se uma enorme demanda de vagas nas universidades ou faculdades, a provocar a proliferação das instituições privadas ${ }^{2}$ de ensino superior, a maioria sem padrões razoáveis de qualidade, mas que continuam funcionando sem qualquer óbice à obtenção de licença ou mesmo ao reconhecimento dos seus diplomas.

Esta pesquisa busca analisar as principais causas da má qualidade do ensino jurídico no Brasil e, ao final, pretende-se apresentar soluções que possam ser úteis para revigorar a atividade desempenhada nos bancos acadêmicos.

\section{A Realidade do Ensino Jurídico no Brasil}

O professor é o profissional que ministra aulas, professa ideias, em cursos de todos os níveis educacionais: Educação infantil, Educação fundamental, Ensino médio e superior, além do Ensino profissionalizante e técnico. Em 15 de outubro se comemora o Dia do Professor. Trata-se de uma das profissões mais antigas do mundo ${ }^{3}$.

O ensino do Direito, se encarado como um sistema fechado em si mesmo, pode se tornar um conhecimento ultrapassado, em desconexão com o dinâmico substrato econômico, social e cultural com o qual convive: "pobre de conteúdo e pouco reflexivo, o ensino jurídico hoje se destaca por uma organização curricular meramente 'geológica'." (FARIA, 1995, p. 102).

O Direito é uma ciência social, porque seu objeto consiste em relações sociais normatizadas, e aplicada, posto que se ocupa em dar solução a problemas práticos dos seres humanos. (MONTEIRO, 2001, p.42). Veja-se o que afirma Getulino do Espírito Santo Maciel:

O ensino não se qualifica em si e por si mesmo, mas em relação a uma sociedade mais ampla com determinados valores, padrões de comportamento,

${ }^{2}$ Cf. AGUIAR, Roberto A. R. de. Habilidades: ensino jurídico e contemporaneidade. Rio de Janeiro: DP\&A, 2004, p.183.

${ }^{3}$ Sobre o histórico da profissão de professor: Cf. NÓVOA, Antônio. O passado e o presente dos professores. In: Profissão professor. 2. ed. Porto: Porto editora, 1998, p.15-21. 
modelos de referências e expectativas. O conhecimento dessa realidade abrangente poderá fornecer parâmetros para a medição da qualidade que se deseja implementar. (MACIEL, 1995, p. 92).

O exercício das profissões jurídicas, principalmente a advocacia, encontra proteção e reconhecimento expressos no texto constitucional, o qual, no seu art. 133, identifica o advogado como "indispensável à administração da justiça”. Para Álvaro de Mello Filho (1977, p.13), a graduação em Direito visa a desenvolver o conhecimento básico da ciência jurídica paralelamente à formação profissional, com o instrumento teórico-prático.

Recomenda-se ainda atentar para o fato de que a base teórica do Direito está alicerçada no mundo do "dever-ser", ou seja, uma seara construída mediante abstrações, com a finalidade precípua de regular a convivência entre os homens. Para Tércio Sampaio Ferraz Jr. (1994, p. 21), estudar Direito "sem paixão é como sorver um vinho precioso apenas para saciar a sede. Mas estudá-lo sem interesse pelo domínio técnico de seus conceitos, seus princípios, é inebriar-se numa fantasia inconsequente".

Faz-se necessária uma abordagem sobre a seleção das diretrizes curriculares para o ensino jurídico e os instrumentos de avaliação da qualidade dos cursos, tudo inserido no contexto dentro do qual o ensino é oferecido e trabalhado, pois "o preparo do corpo docente e a dedicação à carreira de professor universitário são aspectos que não podem e não devem subtrair-se ao nosso controle, sob o risco de omissão". (LEITE, 1995, p. 18).

Fala-se hoje em uma democratização do ensino jurídico (ENCARNAÇÃO, 1995, p. 107), no sentido de que um diploma de Bacharel em Direito está ao alcance de um número cada vez maior de pessoas. Tércio Sampaio Ferraz Jr. (2006, online) entende que o problema do grande número de estudantes tem de ser enfrentado por um controle maior da qualidade em termos de uma melhor fiscalização das faculdades/universidades, e não diminuindo o número de profissionais de Direito ou de estudantes, mas sim buscando fórmulas de adaptação às diferentes necessidades.

Para Luiz Flávio Gomes (2009, on line), o ensino jurídico no nosso país acha-se submetido a pelo menos três crises: científico-ideológica, político-institucional e metodológica, ao arrematar que:

O bom professor hoje (especialmente em cursos de graduação ou de extensão universitária) é o que parte da definição de um problema concreto, reúne tudo quanto existe sobre ele (doutrina, jurisprudência, estatísticas etc.) e transmite esses seus conhecimentos com habilidade (que requer muito treinamento), em linguagem clara, direta, objetiva e contextualizada, direcionando-a (adequadamente) a cada público ouvinte. Além de tudo isso, ainda é fundamental 
administrar o controle emocional (leia-se: deve estar motivado para transmitir tudo que sabe a um aluno que deve ser motivado para aprender). (GOMES, 2009, online).

Deve-se ainda atentar para o fato de que a maioria dos professores dos cursos de Direito não são exclusivos do magistério, pois ocupam cargos públicos ou se dedicam à advocacia ostensiva. Essa é uma realidade que reflete no ensino jurídico, o qual se restringe a aulas monologas e baseadas nos relatos da experiência profissionais dos docentes, tornando parcial a transmissão dos conhecimentos $^{4}$. Ao comentar sobre esse fenômeno do ensino jurídico, Álvaro de Mello Filho contabiliza esses dados, expondo sua visão crítica:

No início da década de 90, as estatísticas davam conta de que no Brasil havia 186 cursos de Direito no país, os quais mantinham a mesma estrutura curricular tradicional desde a reforma de 1973. O resultado dessa política era a existência de um ensino reprodutor, deformador e insatisfatório na preparação de bacharéis para um mercado profissional saturado. (MELLO FILHO, 1993, p. 09).

Tem-se um lado positivo, que é proporcionar o acesso ao ensino superior à grande parte da sociedade, mas também ostenta uma feição negativa que merece ser destacada.

Parte-se da premissa de que o aluno, via de regra, conclui o ensino médio com debilidade em sua capacidade reflexiva pela falta de leitura e sem o domínio da linguagem a ser utilizada no âmbito jurídico, o que provoca um desinteresse por este estudo específico. Por esta razão, os discentes não valorizam as leituras e acabam por desperdiçar a discussão.

A partir do terceiro e quarto semestres letivos, os alunos entram em um processo de desilusão, porque começam a perceber as inadequações do ensino em relação à vida profissional. A tarefa do professor, nessas situações, é incentivá-los a perceber que o curso de Direito exige leitura, estudo e reflexão, não havendo nada que possa substituir o papel a ser cumprido por essas atividades durante o processo de aprendizagem. Deve ainda demonstrar que o estudante está inserido em um sistema que precisa ser compreendido em sua globalidade:

A experiência docente nos cursos jurídicos tem mostrado um fenômeno assustador: o desvanecimento do vigor, do interesse, da curiosidade e da indignação dos alunos, na razão direta de seu avanço no curso. No início, seus olhos brilham, sua curiosidade é aguda, suas antenas estão ligadas para o que acontece no mundo, chegando a assumir posições políticas transformadoras. Aos poucos, na medida em que galgam outros patamares do curso, passam a se ensimesmar, a perder seu afã transformador, abandonando a informalidade criativa e adotando

4 Cf. MELLO FILHO, Álvaro. Metodologia do ensino jurídico. Fortaleza: UFC, 1977, p. 14 e 51. 
uma indumentária padronizada, uma linguagem estandardizada, marcada por uma retórica ultrapassada, sendo seus sonhos abandonados e substituídos por desejos curtos de passar em concursos ou pertencer a exitosas bancas de advogados para ganhar dinheiro e conquistar a tão decantada segurança burguesa. Seus olhos já não têm mais brilho, sua criatividade desapareceu como habilidade de urdir soluções novas, pressupostos diferentes e teorias transformadoras. Em suma, aquele jovem que entrou na universidade transformou-se, em poucos anos, em um velho precoce. (AGUIAR, 2004, p. 186).

Um dos resultados mais impactantes desse desinteresse/desânimo são as reprovações nos Exames de Ordem e concursos públicos, de um modo geral. Para exemplificar esta constatação com dados oficiais, o Conselho Nacional de Educação (lei 9.131/95), que é um órgão colegiado integrante da estrutura de administração direta do MEC, firmou uma parceria entre o Ministério da Educação e a Ordem dos Advogados do Brasil (OAB) para acompanhar a qualidade dos cursos de Direito.

O MEC faz o cruzamento dos resultados preliminares do Sistema Nacional de Avaliação da Educação Superior (SINAES), em especial do Exame Nacional de Desempenho de Estudantes (ENADE) com os dos Exames de Ordem, com o objetivo de melhorar a qualidade do ensino jurídico no País. Em 2006, um total de 89 instituições de ensino superior foram apontadas pelo baixo desempenho na graduação em Direito e receberam notificação do Ministério da Educação.

\section{O Procedimento Adotado no Ensino Jurídico}

O professor-jurista, ao elaborar ou professar teorias, limita-se à exegese do Direito posto, recusando-lhe a crítica e apresentando aos alunos um sistema pronto e acabado, supostamente harmônico, que possuiria todas as respostas jurídicas possíveis. Não orienta seus alunos a buscar o porquê daquelas determinações legais ministradas. Essas abstrações não só levam a um progressivo distanciamento da realidade, mas também a uma fórmula positivista reducionista. (FARIA, 1987, p.28).

Para Paulo Freire (1996, p.33), "educar é substantivamente formar". O ensino jurídico é um processo educacional e, como tal, deve se pautar pela ética (FREIRE, 1996, p.32), pois está em jogo a formação intelectual dos envolvidos. Tércio Sampaio Ferras Jr. enfatiza que:

É preciso reconhecer que, nos dias atuais, quando se fala em Ciência do Direito, no sentido do estudo que se processa nas Faculdades de Direito, há uma tendência em identificá-la com um tipo de produção técnica, destinada apenas a atender às necessidades profissionais (o juiz, o advogado, o promotor)

5 Cf. Conselho Nacional de Educação: <http://portal.mec.gov.br>. 
no desempenho imediato de suas funções. Na verdade, nos últimos cem anos, o jurista teórico, pela sua formação universitária, foi sendo conduzido a esse tipo de especialização fechada e formalista. (FERRAZ JR., 1994, p. 49).

A crise do Direito, portanto, está ligada diretamente à forma pela qual o conhecimento é repassado e assimilado. Por essa razão, os estudantes, já nos primeiros semestres do curso, se manifestam para que lhes seja propiciado acesso à «prática», encarando o estudo do Direito como um simples manusear de processos, assistir a audiências ou elaborar petições. É a ideia da "educação bancária", concebida por Paulo Freire (1987) como o procedimento metodológico de ensino que privilegia o ato de repetição e memorização do conteúdo ensinado. Assim, o docente, figurativamente, por meio de aulas expositivas, deposita na cabeça do aluno conceitos a serem exigidos, posteriormente, na avaliação, quando então, aquele obtém o extrato daquilo que foi "depositado".

Em alguns estabelecimentos de ensino superior existem os núcleos de prática jurídica ${ }^{6}$, com disciplinas obrigatórias vinculadas ao comparecimento dos alunos em estruturas destinadas à realização de atendimento jurídico à comunidade. A opinião de Sérgio Rodrigo Martinez (2009a, on line) merece explanação, principalmente pela ponderação aplicada à questão:

Quanto à proliferação dos cursos de Direito, penso que esta preocupação deve se voltar mais para as instituições de ensino que pedem a criação de novos cursos. Em relação aos cursos já existentes, estes devem se aprimorar cada vez mais a fim de ocuparem lugar de destaque no cenário jurídico e educacional brasileiro.

Embora tenha um aspecto social relevante, - o acesso gratuito da comunidade à prestação jurisdicional e o treinamento dos alunos em lidar com o público carente - reforça ainda mais o afastamento da teoria e a proximidade com a prática forense:

A estruturação pedagógica atrasada, as aulas ministradas em salas lotadas, a pouca exigência acadêmica condenam esses cursos ao papel de formadores de despachantes, que operam perifericamente com as normas, usando seu fraco bom-senso, já que não tratam os comandos normativos com um mínimo de rigor. Essa fragilidade dos cursos faz com que seus professores só trabalhem com textos, no máximo referidos às vivências pessoais dos docentes, tudo isso iluminado pelas poucas velas de doutrinas ultrapassadas e preconceitos camuflados. (AGUIAR, 2004, p.185).

6 Para Roberto A. R. de Aguiar (2004, p. 187), a abertura dos cursos de Direito para a comunidade e o diálogo com as práticas profissionais no desempenho desta atividade são simuladas e representam imitações mais pobres das aulas teóricas, referindo-se a processos idos, a problemas passados, envolvendo sujeitos desconhecidos. 
Essa concepção se disseminou nas universidades, de modo a ignorar que o Direito é, antes de qualquer coisa, um fenômeno cultural. Essencialmente filosófico, antropológico e sociológico, o estudo jurídico não pode ser reduzido à característica de curso de "prática forense". Nessa ótica, "o Direito fica no meio do caminho, como técnica esvaziada. Ignora o seu nascedouro na essência do seu 'ser social' e não desemboca na realidade prática da vida social'. (ENCARNAÇÃO, 1995, p. 114).

Para Paulo Freire (1996, p. 30), é importante o dever do professor em respeitar e saber aproveitar o conhecimento dos alunos, a carga informativa com a qual eles chegam aos bancos acadêmicos e discutir a razão de ser destes fatos.

Se não for assim, verificar-se-á um ciclo vicioso a indicar o caminho enviesado a seguir: uma postura dogmática e tradicional dos docentes e uma formação direcionada dos discentes em favor de um contexto excludente de mercado, díspar da realidade social. (MARTINEZ, 2009b, on line). Também ressalta que o papel do docente tem que despertar a curiosidade dos discentes como uma das "tarefas precípuas da prática educativo-progressista". Nas suas palavras:

Por que não aproveitar a experiência que têm os alunos de viver em áreas da cidade descuidadas pelo poder público para discutir, por exemplo, a poluição dos riachos e dos córregos e os baixos níveis de bem-estar das populações, os lixões e os riscos que oferecem à saúde das gentes. Por que não há lixões no coração dos bairros ricos e mesmo puramente remediados dos centros urbanos? Esta pergunta é considerada em si demagógica e reveladora da má vontade de quem a faz. É pergunta de subversivos, dizem certos defensores da democracia. Por que não discutir com os alunos a realidade concreta a que se deva associar a disciplina cujo conteúdo se ensina, a realidade agressiva em que a violência é a constante e a convivência das pessoas é muito maior com a morte do que com a vida? Por que não estabelecer uma 'intimidade' entre os saberes curriculares fundamentais aos alunos e a experiência social que eles têm como indivíduos? (FREIRE, 1996, p. 30).

Aprender ${ }^{7}$ significa tomar conhecimento de algo, reter na memória a observação ou a experiência. $\mathrm{O}$ incentivo à pesquisa é um dos melhores métodos para se associar novas ideias ao conhecimento a ser adquirido pelo corpo discente. Em linguagem poética, Luiz Edson Fachin argumenta que:

No horizonte a vencer, o que se diz é tão relevante quanto como se diz. Daí, a perspectiva inadiável de revirar a práxis didática. Sair da clausura dos saberes postos à reprodução e ir além das restrições que o molde deforma. (FACHIN, 2000, p. 06).

\footnotetext{
7 Cf. FERREIRA, Aurélio Buarque de Holanda. Novo Aurélio: o dicionário da língua portuguesa. 3. ed.
} Rio de Janeiro, 1999, p.171. 
Isso é possível através da construção de grupos de trabalho (GT), grupos de discussão (GD) sob a supervisão e mediação do professor, de modo a promover a discussão, o debate e o entrosamento entre as turmas e os docentes acerca de determinado assunto ou tema ligado à disciplina ministrada. $\mathrm{O}$ contato dos professores com os seus aprendizes é fundamental para que se possa saber como os ensinamentos estão sendo transmitidos e recebidos, uma espécie de termômetro, além de incrementar o nível intelectual dos estudantes e a didática dos mestres.

\section{Como Melhorar o Ensino Jurídico no Brasil?}

O MEC, com o escopo de regular as diretrizes curriculares mínimas para os cursos de Direito no Brasil, editou a Portaria ${ }^{\circ} 1.886 / 94$, a qual abriu caminhos para elaboração da lei de Diretrizes e Bases da Educação (Lei 9.394/96) e para a criação de um sistema de avaliação do ensino superior sob o encargo do Estado, cujos maiores instrumentos seriam o Exame Nacional de Cursos (Lei 9.131/95).

O intervencionismo estatal reforçou uma política de fiscalização e avaliação periódica das Instituições de Ensino Superior, o que gerou repercussões positivas no cenário educacional do Direito. Medidas como a exigência de apresentação da monografia final, o cumprimento de carga horária de atividades complementares e a obrigatoriedade de cumprimento do estágio de prática jurídica (os NPJs - Núcleos de Prática Jurídica), a exigência de que cada curso de Direito mantivesse um acervo jurídico de, no mínimo, dez mil volumes de obras jurídicas e referência às matérias do curso, além de periódicos de jurisprudência, doutrina e legislação, são alguns exemplos dessa nova postura.

Analisando a Portaria № 1886/94, Horácio Vanderlei Rodrigues (1995, p.122) afirma que os seus pressupostos são os seguintes: a superação da concepção de que só é profissional de Direito aquele que exerce atividade forense; a negação de autossuficiência ao Direito; a superação da concepção de educação como sala de aula; a necessidade de um profissional com formação integral (interdisciplinar, teórica, crítica, dogmática e prática).

Aponta-se neste breve estudo, sem a intenção de esgotar a matéria, algumas medidas que possam melhorar o ensino jurídico, atentando-se para as peculiaridades brasileiras. Primeiro, recomenda-se a instalação de fóruns permanentes de discussão e debate sobre o ensino jurídico, com a participação de representantes de diversos cursos de Direito e centros acadêmicos, de representantes do Ministério Público e de instituições de classe, de modo a relacionar as questões mais importantes que circundam o meio jurídico. 
Outra medida que pode ser adotada com sucesso é a inovação nos métodos didáticos aplicados no ensino jurídico para que seja despertada a consciência crítica do aluno no tocante ao conhecimento transmitido pelo professor, a fim de que o discente adquira uma postura ativa, e não passiva, em sala de aula, participe dos debates mais significativamente e se sinta mais inserido na academia.

Ressalta-se ainda a necessidade de demonstrar ao estudante de Direito como provocar a conscientização de sua própria função social de operador jurídico, de modo que os alunos não devem somente vislumbrar os seus interesses, que almejam quando da conclusão do curso: o principal objetivo deve ser no sentido de melhorar a qualidade e a imagem da profissão jurídica, em todos os ramos. Isso demonstra a necessidade de uma postura pautada por novas propostas, que sejam capazes de modificar o modelo existente na atualidade.

Fala-se em uma abordagem desse viés na função social da universidade $^{8}$, um conceito que direciona a atividade universitária - para docentes e discentes - no sentido de se orientar por meio de um planejamento decorrente da reflexão individual ou em grupo, na realização de reuniões periódicas para refletir, discutir, escrever e expor a questão interdisciplinar das matérias lecionadas, ou seja, ver a disciplina a partir de uma visão em perspectiva histórico-cultural. Desse modo, capacita-se o docente a transmitir os conhecimentos adquiridos e refletidos, focando o aluno nesse processo. Inovar no método didático é extremamente importante para se elevar o nível intelectual dos alunos.

Álvaro de Mello Filho (1977, p. 33-34) apresenta um quadro esquemático que bem define os passos que devem ser seguidos para uma melhoria significativa do ensino jurídico: habituar o discente ao raciocínio jurídico; a valorização da consciência e mentalidade; debater para saber pensar; o olhar para o aluno. Reputa como palavras mais e menos importantes para o aprendizado, respectivamente: o dialogar e o monologar.

Com uma mudança na mentalidade dos envolvidos no processo de ensino-aprendizagem, ou seja, se os professores agissem pautados pelo compromisso ético de transmitir o conhecimento respeitando a bagagem intelectual do aluno, certamente a qualidade do ensino, em especial o jurídico, seria bem superior. Na verdade, esta crise que se está a tratar em grande parte se relaciona com a própria vivência humana e atinge praticamente todas as áreas do conhecimento. Assim, não se pode focalizar a má qualidade do ensino jurídico sem enquadrá-lo na crise geral que afeta a sociedade.

8 Cf. RIGHETTI, Moacir Spadoto. O ensino jurídico e a função social da universidade. Disponível em: <http://www.conpedi.org/manaus/brasilia/>. Acesso em: 19 maio 2009. 


\section{Conclusão}

O ensino jurídico precisa ser repensado. Por ser um processo que provoca mudanças de mentalidade e reflexos sociais, econômicos e políticos, ressalta-se a importância desse processo vital para o desenvolvimento humano. Cada vez mais saem dos bancos acadêmicos profissionais do Direito sem as mínimas condições para o exercício das habilidades em relação às quais o curso propõe-se a capacitar.

Certamente que não se conseguirá superar os graves problemas que afetam a sociedade e, mesmo havendo uma profunda reformulação no sistema educacional, este sempre refletirá as relações que são mantidas na tessitura social. Ensinar o Direito não significa simplesmente reproduzir os dogmas, as teorias, a letra da lei. Ao contrário, a função principal do professor é problematizar a realidade que o cerca, bem como seus alunos, para, calcado nesta premissa, apontar caminhos para a construção de um Direito promotor de verdade e justiça.

Pretendeu-se destacar nesta breve pesquisa a necessidade de se permitir uma liberdade maior no processo de ensino-aprendizagem, de modo a incutir no aluno o interesse pela pesquisa e, consequentemente, a busca por suas próprias conclusões, sem estar limitado pelas amarras de uma sistemática de via única, em que só o professor é o detentor do conhecimento. Não deve ser assim, pois a ideia é ensinar para a vida de modo a se alcançar uma transformação mais significativa da realidade social.

\section{REFERÊNCIAS}

AGUIAR, Roberto A. R. de. Habilidades: ensino jurídico e contemporaneidade. Rio de Janeiro: DP\&A, 2004.

ENCARNAÇÃO, João Bosco da. A questão do ensino jurídico. In: ENCARNAÇÃO, João Bosco da. MACIEL, Getulino do Espírito Santo (orgs.). Seis temas sobre o ensino jurídico. São Paulo: Cabral, 1995.

FACHIN, Luiz Edson. Teoria crítica do direito civil. Rio de Janeiro: Renovar, 2000.

FARIA, José Eduardo. O ensino jurídico. In: ENCARNAÇÃO, João Bosco da. MACIEL, Getulino do Espírito Santo (Org.). Seis temas sobre o ensino jurídico. São Paulo: Cabral editora, 1995.

1987.

. A Reforma do Ensino Jurídico. Porto Alegre: Sérgio Antônio Fabris, 
FERRAZ JR., Tércio Sampaio. Introdução ao Estudo do Direito: técnica, decisão e dominação. 2. ed. São Paulo: Atlas, 1994.

. A visão crítica do ensino jurídico. Acesso em: 28 abr. 2009. Disponível em < www.terciosampaioferrazjr.com.br $>, 2006$.

FERREIRA, Aurélio Buarque de Holanda. Novo Aurélio: o dicionário da língua portuguesa. 3. ed. Rio de Janeiro, 1999.

FREIRE, Paulo. Pedagogia como autonomia: saberes necessários à prática educativa. 30. ed. São Paulo: Paz e Terra, 1996.

. Pedagogia do oprimido. 27. ed. Rio de Janeiro: Paz e Terra, 1987.

GOMES, Luiz Flávio. A crise (tríplice) do ensino jurídico. Disponível em: <www.jusnavigandi.com.br>. Acesso em: 19 maio 2009.

LEITE, Eduardo de Oliveira. A aula em Direito. In: ENCARNAÇÃO, João Bosco da. MACIEL, Getulino do Espírito Santo (Org.). Seis temas sobre o ensino jurídico. São Paulo: Cabral editora, 1995.

MACIEL, Getulino do Espírito Santo. Por um ensino jurídico crítico. In: ENCARNAÇÃO, João Bosco da. MACIEL, Getulino do Espírito Santo (Org.). Seis temas sobre o ensino jurídico. São Paulo: Cabral editora, 1995.

MARTINEZ, Sérgio Rodrigo. Reflexões sobre o Ensino Jurídico: aplicação da obra de Paulo Freire aos cursos de Direito. Revista Âmbito Jurídico. Disponível em: < www.ambito-juridico.com.br>. Acesso em: 22 maio 2009a.

. A evolução do ensino jurídico no Brasil. Disponível em <www. ensinojuridico.com.br>. Acesso em: 19 maio 2009b.

MELO FILHO, Álvaro. Por uma revolução no ensino jurídico. Revista Forense. Rio de Janeiro, v.322, ano 89, abr./jun. p.09-15, 1993.

. Metodologia do ensino jurídico. Fortaleza: UFC, 1977.

MONTEIRO, Geraldo Tadeu Moreira. Metodologia da pesquisa jurídica: manual para a elaboração e apresentação de monografias. Rio de Janeiro, 2001.

NÓVOA, Antônio. O passado e o presente dos professores. In: Profissão professor. 2. ed. Porto: Porto editora, 1998.

RIGHETTI, Moacir Spadoto. O ensino jurídico e a função social da universidade. Disponível em: <http://www.conpedi.org/manaus/brasilia/>. Acesso em: 19 maio 2009. 
RODRIGUES, Horácio Wanderlei. A reforma curricular nos cursos jurídicos e a portaria n. ${ }^{\circ}$ 1.886/94MEC. In: I Seminário Nacional de Ensino Jurídico, Cidadania e Mercado de Trabalho. Curitiba: UFPR - Faculdade de Direito, 1995, p.117-126.

\section{AN ANALYSIS OF LEGAL EDUCATION IN BRAZIL}

Abstract: This is an analysis of legal education in Brazil, investigating the main reasons for its poor quality. At first, it is made a brief contextualization of the situation of instructors and students in the courses of law, with a greater focus on the democratization of education, particularly the legal one, to investigate the advantages and disadvantages of this phenomenon. In conclusion, there is a need for greater control of such learning process by authorities in order to provide an increasingly contribution to society.

Keywords: Legal education. Democratization. Supervision. Ethics.

Data de recebimento: jan/2011 - Data de aprovação: mar/2011 